\title{
A WebGIS portal for exploration of deep geothermal energy based on geological and geophysical data
}

\author{
Henrik Vosgerau, Anders Mathiesen, Morten Sparre Andersen, Lars Ole Boldreel, Morten Leth \\ Hjuler, Elina Kamla, Lars Kristensen, Christian Brogaard Pedersen, Bjarni Pjetursson and \\ Lars Henrik Nielsen
}

The Danish subsurface contains deep geothermal resources which may contribute for hundreds of years to the mixed Danish energy supply (Mathiesen et al. 2009). At present only a limited fraction of these resources are utilised in three existing geothermal power plants in Thisted, Margretheholm and Sønderborg (Fig. 1) where warm formation water is pumped to the surface from a production well and, after heat extraction, returned to the subsurface in injection wells (Fig. 2). Deep geothermal energy has the advantage of being a sustainable and environmentally friendly energy source which is furthermore independent of climate and seasonal variations, in contrast to wind and solar energy. The implementation of deep geothermal energy for district heating replacing conventional energy sources, especially coal and oil, may thus lead to a considerable reduction in the emission of greenhouse gases. There

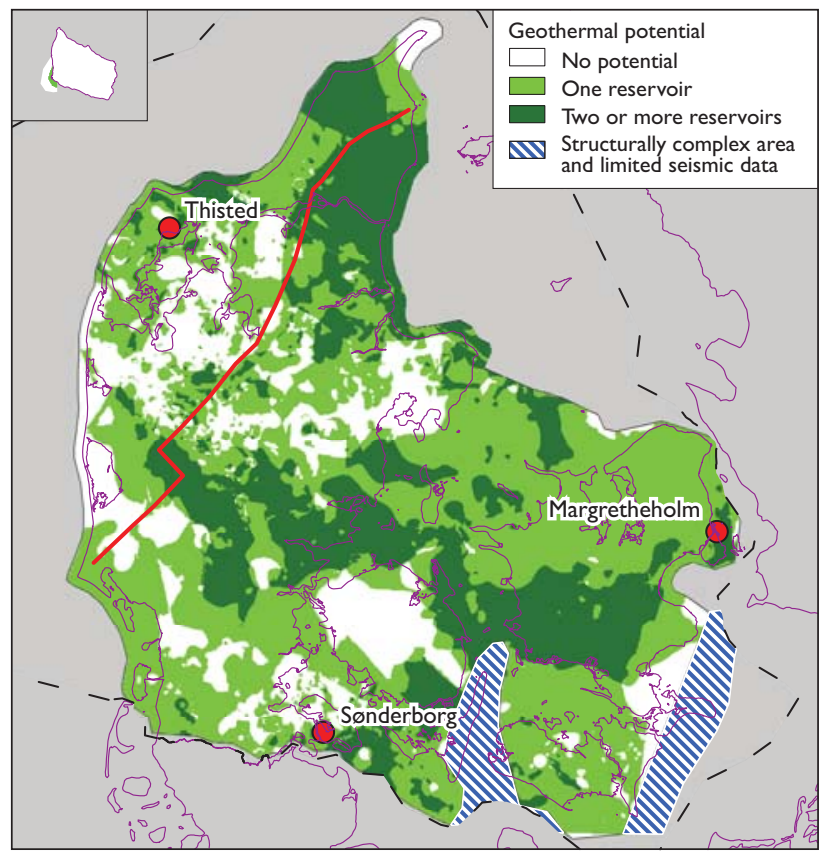

Fig. 1. Distribution of lithostratigraphic units with reservoir properties suitable for geothermal exploration in the geothermal depth zone (800-3000 m), see the main text. The red line indicates the transect covered by the geosection shown in Fig. 5. Positions of the operating geothermal plants are shown. are therefore good reasons to include geothermal energy as a central component in Denmark's future supply of energy for district heating. Furthermore, heat-demanding industries may consider the possibility to integrate geothermal energy and energy storage in their production process.

In order to facilitate the use of geothermal energy, a broad majority in the Danish parliament has granted financial support for initiatives within the geothermal field (Energy policy agreement of March 22, 2012). The present paper deals with one of the outcomes of this agreement, namely a WebGIS portal with an overview of existing and

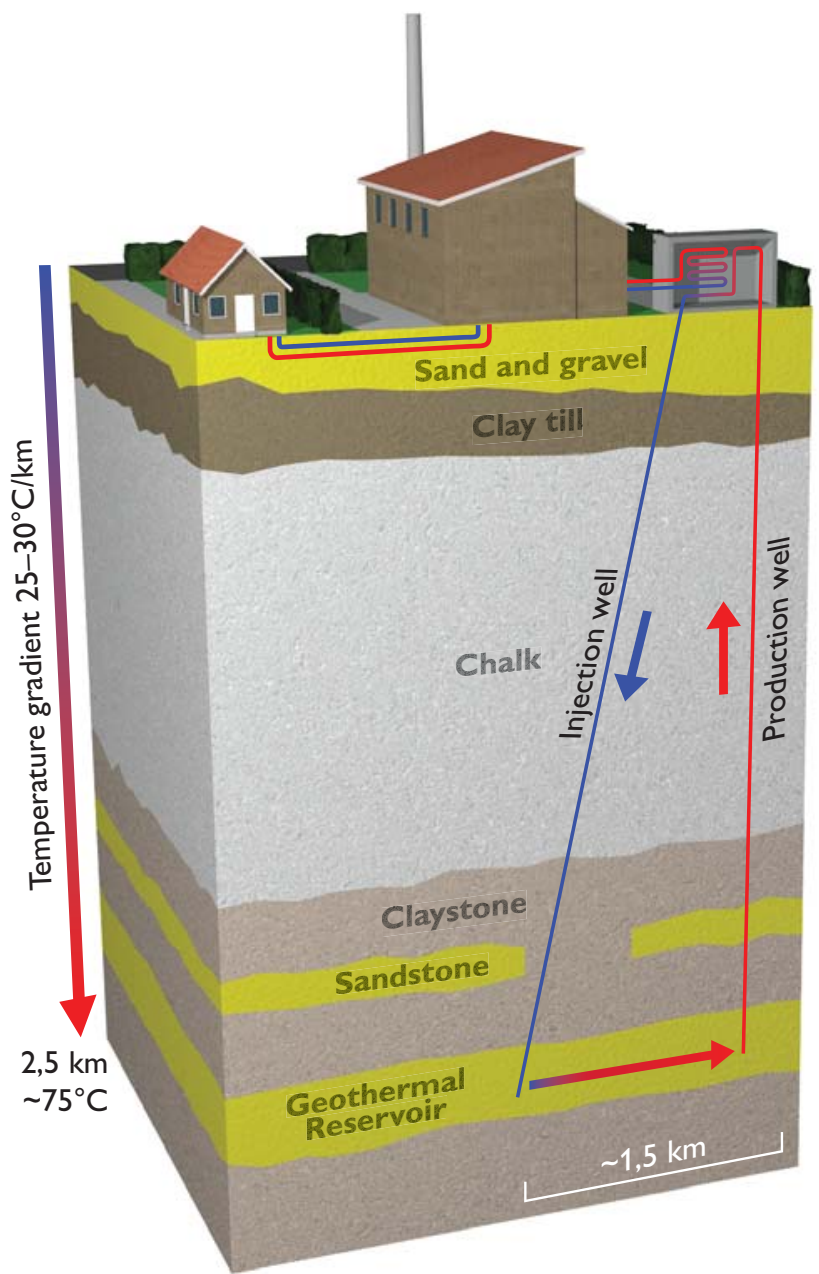

Fig. 2. Principle sketch of a geothermal power plant with production and injection wells to a deep-seated geothermal sandstone reservoir. 


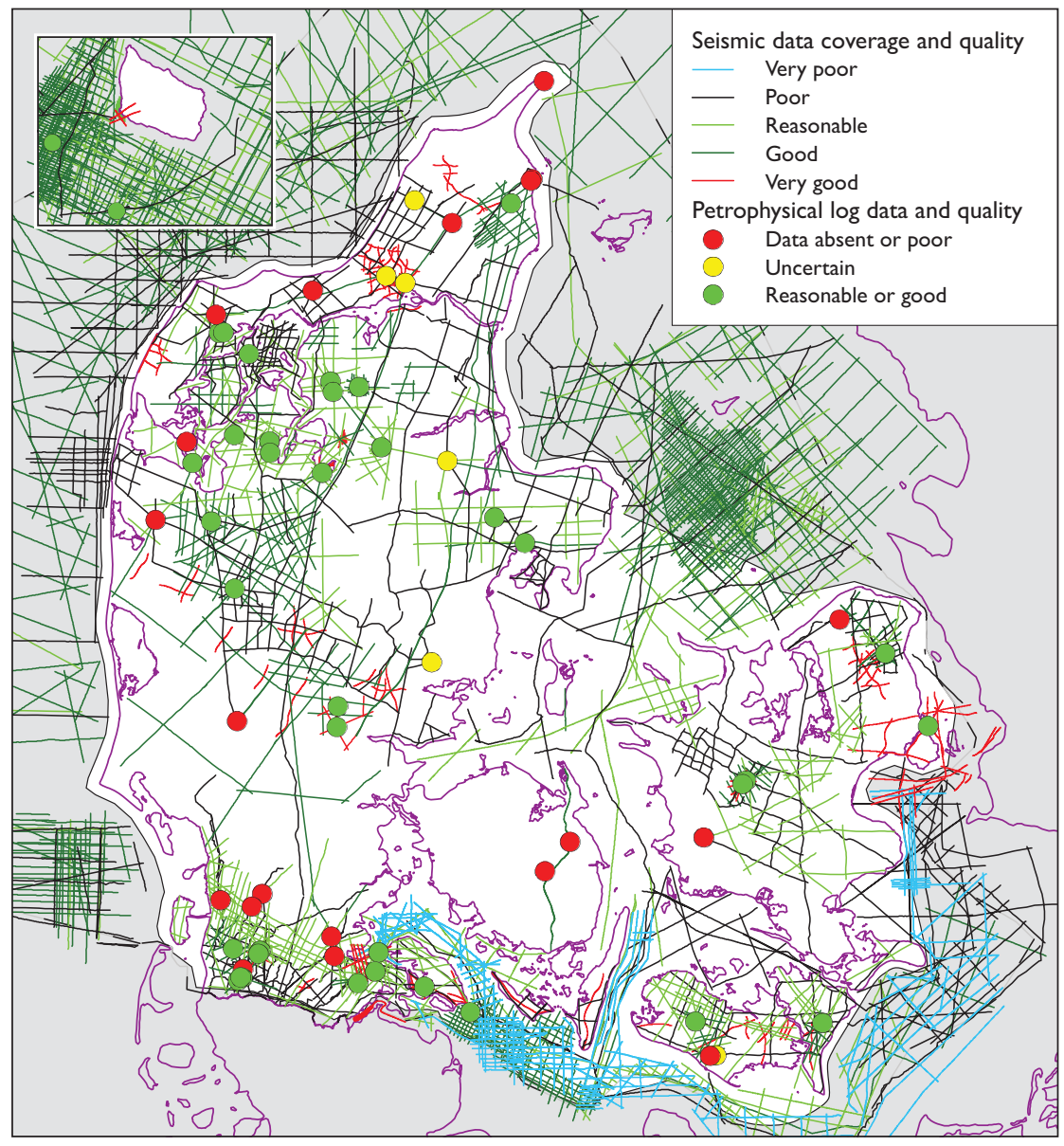

Fig. 3. Coverage and quality of seismic and petrophysical log data from deep wells. The quality indexes reflect to which degree the data can be used to extract information about geothermal relevant lithostratigraphic units in the deep subsurface.

interpreted geological and geophysical data. This will be relevant for all stakeholders in the exploration of deep geothermal resources in the Danish subsurface. The portal focuses on geothermal reservoirs within the $800-3000 \mathrm{~m}$ depth interval and provides an overview of the amount and quality of existing geodata, the geological composition of the subsurface, and interpreted thematic products such as geological maps of potential geothermal reservoirs. A comprehensive map from the portal showing onshore and nearoffshore locations where the geological conditions are potentially suitable for extraction of deep geothermal energy in Denmark is shown in Fig. 1. Many of the thematic maps are outcomes of the project The geothermal energy potential in Denmark - reservoir properties, temperature distribution and models for utilization under the programme Sustainable Energy and Environment funded by the Danish Agency for Science, Technology and Innovation.

\section{Geological requirements for geothermal exploitation}

In Denmark, successful geothermal exploitation in the deep subsurface requires the presence of thick and later- ally coherent sandstone reservoirs with high porosity and permeability, which can ensure effective extraction and re-injection of formation water. A thick and coherent reservoir which is not hydraulically compartmentalised by faults, lateral lithological changes (e.g. grain size) and/or diagenetic features such as compaction and mineralisation implies that a large volume of warm water may be accessible, and that production and injection wells can be placed at appropriate distances from each other while remaining hydraulically connected. A certain distance, e.g. $1,5 \mathrm{~km}$, is needed between the filter screens at reservoir level in order to delay the arrival time of the cool, re-injected water to the vicinity of the production well (Fig. 2). As a rule of thumb this delay should be more than 30 years. On its way to the production well, the cooled water is reheated to some extent by the reservoir matrix and by heat transfer from poorly or non-permeable boundary strata (usually claystone) above and below the reservoir sandstones.

Another important requirement is to find areas where the product of temperature and extractable water volume is large enough to ensure an economically viable geothermal plant. The temperature-depth gradient of $25-30^{\circ} \mathrm{C} / \mathrm{km}$ in the Danish subsurface implies that at depths shallower 


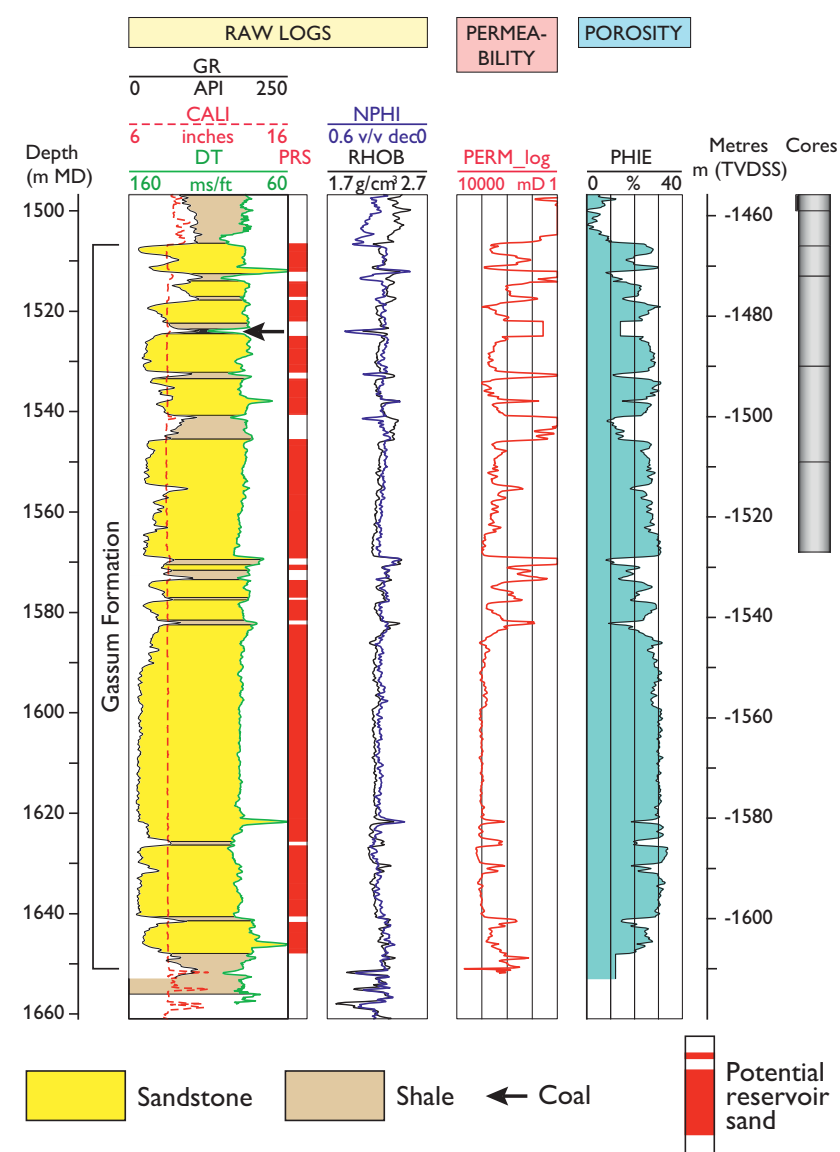

Fig. 4. Petrophysical log evaluation of the Gassum Formation in the Stenlille-1 well including interpretations of lithology, porosity and permeability. GR: Gamma-ray log. API: Gamma ray radioactivity expressed in accordance with the American Petroleum Institute. CALI: Caliper log. DT: Sonic log. PRS: Potential reservoir sand. NPHI: Total porosity log. RHOB: Density log. PERM_log: Permeability log. PHIE: Effective porosity log. MD: Measured depth. TVDSS: Vertical depth below sea level. than $800 \mathrm{~m}$ the temperature is generally too low, whereas at depths greater than $3000 \mathrm{~m}$, diagenetic alterations related to high pressure-temperature conditions reduce the porosity and permeability of the reservoir sandstones (Poulsen et al. 2015; Kristensen et al. 2016). Hence, the focus of the portal is the $800-3000 \mathrm{~m}$ depth interval.

\section{The geological database}

The geological data that provide information about Denmark's deep subsurface mainly consist of information from deep wells and seismic surveys collected over a number of years during oil and gas exploration, and to a lesser extent during studies of potential gas storage and geothermal exploration.

The geographical coverage and quality of the data vary considerably as outlined in Fig. 3. Generally, it is possible to obtain detailed information about the penetrated sedimentary successions from the well data including the depth, thickness and reservoir properties of sandstone reservoirs, e.g. based on core data and petrophysical evaluation of well log data (Fig. 4). The seismic data have been used for largescale mapping of the depth, thickness and lateral extent of lithostratigraphic units known to contain geothermal reservoir sandstones, as well as for identification and mapping of major faults (Fig. 5). This work involved compilation and integration of the many seismic surveys of different age and quality into a coherent seismic network. Then the network was interpreted in its entirety and used to generate nationwide depth maps to important subsurface horizons, with conversions from seismic-wave travel time to depths below sea level.

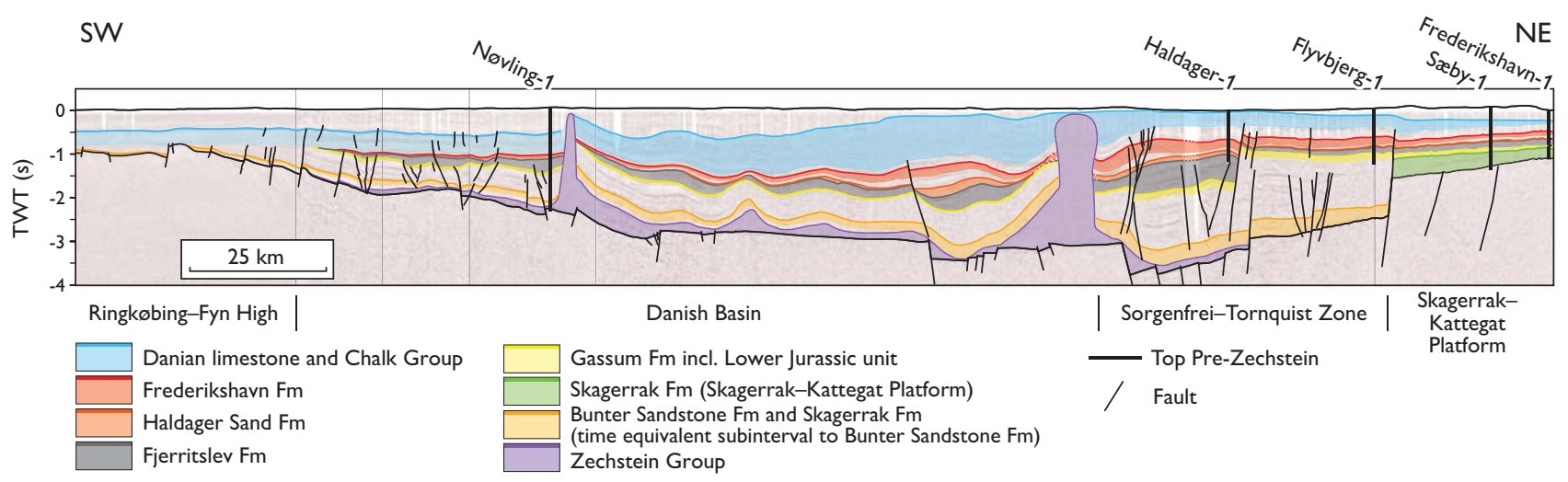

Fig. 5. A regional SW-NE geosection through central and northern Jylland as outlined in Fig. 1. The profile is constructed on the basis of composite seismic profiles shown in the background. Mapped lithostratigraphic units with individual treatment in the portal are highlighted. These include those units which may contain geothermal sandstone reservoirs. In several places the units are truncated by faults, and vertical salt movement from the Zechstein Group has in places uplifted or penetrated the overlying succession. Major structural elements are indicated. Depth is given in seismic two-way travel time (s). 


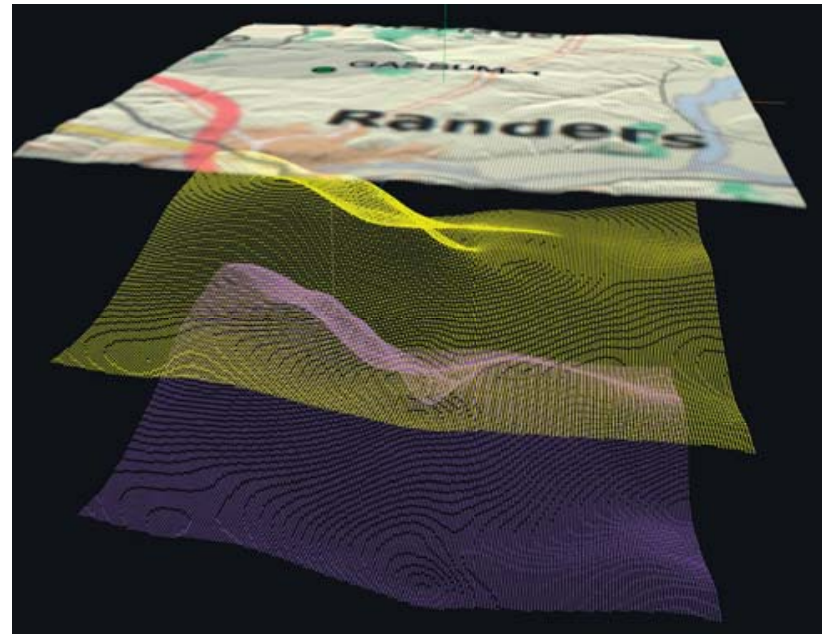

Fig. 6. Interactive 3D tool, available in the WebGIS portal, visualising the variation of subsurface topography of mapped seismic horizons in a given $10 \times 10 \mathrm{~km}$ area around a selected point.

The depth maps were subsequently used as a base for a new set of maps where constrained reservoir properties such as porosity and temperature were added in relation to depth. In general, the amount of data is too limited for traditional statistical uncertainty analysis. However, based on quality and spatial density analysis and GEUS' general experience, rough uncertainty intervals for the estimated reservoir values are presented for each well in the portal.

\section{The WebGIS portal - content, functionality and perspectives}

The first map in the WebGIS portal shows those areas where lithostratigraphic units, containing sandstones with sufficient reservoir properties are considered to be present within the depth interval of 800-3000 m (Fig. 1). The lithostratigraphic units are also treated separately and linked with several relevant theme maps showing e.g. depth, thickness, major faults, reservoir transmissivity and temperature. Additional data, available in the portal, can be added to each of these maps, such as the distribution and quality of seismic data and petrophysical log data from deep wells. The depth maps can also be visualised through an interactive $3 \mathrm{D}$ viewer providing an intuitive overview of the subsurface topography of a selection of important horizons (Fig. 6). These maps are to be considered as indicative and are only meant for regional use. This is because the geological data in many areas only provide a rough picture of the subsurface, especially where data are sparse and/or of poor quality. In addition, some of the maps are based on several stages of approximations and generalisations, for instance where largely depth-depending reservoir parameters are paired with depth maps derived from seismic surveys, as briefly described above.

The maps are not final. New well and seismic data can be added and new interpretation tools such as seismic interpolation tools can be included. Refined geological models may also lead to modifications. However, the present maps give a good indication of where in Denmark deep geothermal exploration is relevant, as seen from the geological prerequisites. The use of the maps may thus ensure that new geothermal exploration is directed towards those areas that appear to be most promising based on current knowledge. The various geological map themes also form an important basis for an initial analysis of the geothermal potential at a specific site where the construction of a geothermal plant is considered. In this first step, the maps give an overview of the potential geothermal reservoir intervals (lithostratigraphic units) that may be relevant at the site, and information regarding the type, amount and quality of existing geological data. A more comprehensive estimate of the geothermal potential in a specific area must be based on detailed analysis of the local data and incorporation into local geological models. This work model has been used in an assessment of 28 potential geothermal sites in Denmark in the so-called Screening project; another outcome of the above-mentioned policy agreement. The results of this work are also accessible free of charge from the WebGIS portal at http://DybGeotermi.geus.dk.

\section{References}

Kristensen, L., Hjuler, M.L., Frykman, P., Olivarius, M., Weibel, R., Nielsen, L.H. \& Mathiesen, A. 2016: Pre-drilling assessments of average porosity and permeability in the geothermal reservoirs of the Danish area. Geotherm Energy 4:6, 2-27, http://dx.doi.org/ 10.1186/ s40517-016-0048-6

Mathiesen, A., Kristensen, L., Bidstrup, T. \& Nielsen, L.H. 2009: Vurdering af det geotermiske potentiale i Danmark. Danmarks og Grønlands Geologiske Undersøgelse Rapport 2009/59, 30 pp.

Poulsen, S.E., Balling, N. \& Nielsen, S.B. 2015: A parametric study of the thermal recharge of low enthalpy geothermal reservoirs. Geothermics 53, 464-478.

\footnotetext{
Author' address

Geological Survey of Denmark and Greenland, Øster Voldgade 20, DK-1350 Copenhagen K, Denmark,. E-mail: hv@geus.dk
} 